\title{
Damage-free Laser Patterning of Silicon Nitride on Textured Crystalline Silicon using an Amorphous Silicon Etch Mask for Ni/Cu Plated Silicon Solar Cells
}

Authors names and affiliations: Mark S. Bailly, Joseph Karas, Harsh Jain, William J. Dauksher, and Stuart Bowden

Department of Electrical, Computer, and Energy Engineering, Arizona State University, Tempe, Arizona 85284-1808, USA

Solar Power Lab, Arizona State University 7700 S River Parkway, 85284-1808, Tempe, USA

Corresponding author: Mark S. Bailly, mbailly@asu.edu, 234 S Lakeview Blvd, Chandler, AZ 85225

\begin{abstract}
We investigate the optimization of laser ablation with a femtosecond laser for direct and indirect removal of SiNx on alkaline textured c-Si. Our proposed resist-free indirect removal process uses an a-Si:H etch mask and is demonstrated to have a drastically improved surface quality of the laser processed areas when compared to our direct removal process. Scanning electron microscope images of ablated sites show the existence of substantial surface defects for the standard direct removal process, and the reduction of those defects with our proposed process. Opening of SiNx and SiOx passivating layers with laser ablation is a promising alternative to the standard screen print and fire process for making contact to Si solar cells. The potential for small contacts from laser openings of dielectrics coupled with the selective deposition of metal from light induced plating allows for high-aspect-ratio metal contacts for front grid metallization. The minimization of defects generated in this process would serve to enhance the performance of the device and provides the motivation for our work.
\end{abstract}

Keywords: laser removal, silicon nitride, plating, textured silicon, sacrificial layer, femtosecond laser

\section{Introduction}

Laser patterning of thin films such as Silicon Nitride $\left(\mathrm{SiN}_{\mathrm{x}}\right)$, Silicon Oxide $\left(\mathrm{SiO}_{\mathrm{x}}\right)$, and hydrogenated amorphous silicon $(\mathrm{a}-\mathrm{Si}: \mathrm{H})$ is desirable for Silicon $(\mathrm{Si})$ solar cell production; it allows for patterning similar to that which is achieved with photolithography at a fraction of the cost and may be used for processes such as contact patterning and selective doping [1-6]. However, a major challenge for a laser ablation process is the c-Si damage typically induced by the laser. While 'low damage' laser patterning is trivial on smooth surfaces, performing such patterning on surfaces textured by the standard mono-crystalline $\mathrm{Si}$ alkaline etch process proves more difficult [7-9].

Knorz et al. demonstrated an order of magnitude variation in laser intensity across pyramidal structures $5-10 \mu \mathrm{m}$ in size [7]. These variations in laser pulse intensity are detrimental towards the ablation process given that Hernandez et al. demonstrated a decrease in generation current $\left(J_{G}\right)$ and open circuit voltage $\left(V_{O C}\right)$ with an increase in laser pulse intensity [1]. Further, the non-uniform heating that can occur causes threading dislocations at the peaks of the pyramids, as deep as $1 \mu \mathrm{m}[8]$.

The removal of $\mathrm{SiN}_{\mathrm{x}}$ with sufficiently high laser powers for film ablation has been shown to affect the mechanical and electrical performance of solar cells. Kluska et al. demonstrated a dependence on the pulse duration of the laser on the peel force of the contacts and showed the 
decrease in adhesion with an increase in pulse duration. Their work relating an increase in theoretical silicide depth with a measured decrease in pseudo-fill factor $(p F F)$ and the work from Büchler et al. - relating an increase in silicide depth with laser processing - indicate the damage formed from laser processing can lead to reductions of $p F F$ in solar cells from deep local nickel silicide formation after annealing $[4,10]$.

We propose a strategy for the indirect removal of $\mathrm{SiN}_{\mathrm{x}}$ by patterning an a-Si:H etch mask with an $800 \mathrm{~nm} 140$ femtosecond laser. Due to the nature of the laser, plasma ablation of the a$\mathrm{Si}: \mathrm{H}$ mask is achievable through the generation of energetic electrons via impact ionization [11].

\section{Material and Methods}

To investigate the effects of direct and indirect ablation of $\mathrm{SiN}_{\mathrm{x}}$ on smooth and textured c-Si we experiment with two different processing schemes.

All substrates were p-type mono-crystalline boron doped wafers with a bulk resitivity of 1-3 $\Omega \cdot \mathrm{cm}$ with a thickness of $170-200 \mu \mathrm{m}$. Bulk resistivity of the substrates and emitter sheet resistances are determined with a kelvin four point probe. Substrates were pseudo square and measure $(156 \pm 0.5) \mathrm{mm}^{2}$. Film depositions were performed with an Applied Materials Precision 5000 plasma enhanced chemical vapor deposition (PECVD) tool. All films were deposited with the conditions listed in table 1 .

\begin{tabular}{|c|c|c|c|c|c|}
\hline $\begin{array}{c}\text { Film } \\
\text { (type })\end{array}$ & $\begin{array}{c}\text { Pressure } \\
(\mathrm{Pa})\end{array}$ & $\begin{array}{c}\text { Power Density } \\
\left(\mathrm{W} / \mathrm{cm}^{2}\right)\end{array}$ & $\begin{array}{c}\text { Temperature } \\
\left({ }^{\circ} \mathrm{C}\right)\end{array}$ & $\begin{array}{c}\mathrm{SiH}_{4} / \\
\mathrm{NH}_{4}\end{array}$ & $\begin{array}{c}\mathrm{SiH}_{4} / \\
\mathrm{H}_{2}\end{array}$ \\
\hline SiNx & 460 & 0.75 & 350 & 1 & N/A \\
\hline a-Si:H & 430 & 0.15 & 300 & N/A & 0.2 \\
\hline
\end{tabular}

TABLE 1. Deposition conditions for thin films deposited with PECVD, $\mathrm{SiN}_{\mathrm{x}}$ was deposited dilute in $\mathrm{N}_{2}$ with no additional hydrogen.

The film stack of $\mathrm{SiN}_{\mathrm{x}}$ and a-Si:H shown in figure 1 (a) is deposited in two identical, but separate chambers of the PECVD tool (connected via a loadlock) with the conditions listed in table 1.

Sequential processing of these films in the same chamber is possible, but was not explored due to possible film flaking issues. Film thicknesses of $\mathrm{SiN}_{\mathrm{x}}$ and a-Si:H are inferred from a weekly statistical process control of deposition rates measured by reflectance measurements of $\mathrm{SiN}_{\mathrm{x}}$ on polished surfaces. For textured surfaces, deposition rates are divided by a factor of 1.6 that was determined by measuring the film thickness using a cross sectional scanning electron microscope (SEM) image.

Laser processing of the thin films is performed with an $800 \mathrm{~nm} 140 \mathrm{fs}$ laser with a repetition rate of $5 \mathrm{kHz}$. Each repetition of the laser generates a pulse train of approximately 6 laser pulses separated by $12.5 \mathrm{~ns}$. All $\mathrm{SiN}_{\mathrm{x}}$ films are deposited with a film thickness of $\sim 80 \mathrm{~nm}$ and a-Si:H films are varied from 5-40 $\mathrm{nm}$ in thickness.

Intensity control of the laser is managed using neutral density reflective filters. When fine control is required, multiple filters are used causing pulse echoing $\leq 1 \%$ of the transmitted power. We neglect this effect as we attribute the ablation process to the peak laser intensity — not the absorbed power-which remains unaffected by sub-peak intensity pulse echoing. Pulse overlap is controlled by the scanning speed of the flying optics used to steer and focus the laser over the Si substrate.

For clarity, we define 'partial ablation' as film removal over the defined laser spot area less than $70 \%$. Regions covered in a thin layer of $\mathrm{SiN}_{\mathrm{x}}$ are considered as non-removed sites and are 
observable in the SEM images presented. All SEM images are produced with a Hitachi S7800 low-voltage SEM with an acceleration voltage of $3 \mathrm{kV}$ and beam current of $10 \mu \mathrm{A}$.

Figure 1 (a) details the processing scheme for direct removal of $\mathrm{SiN}_{\mathrm{x}}$. Direct removal of the $\mathrm{SiN}_{\mathrm{x}}$ at lower power conditions with an $800 \mathrm{~nm}$ photon occurs via vaporization of the underlying $\mathrm{Si}$ due to the lack of photon absorption in the $\mathrm{SiN}_{\mathrm{x}}$ (as shown in figure 2). Vaporization of the substrate can be a damage-intensive process, especially with the laser intensity variation introduced on textured substrates. Figure 1 (b) illustrates the proposed indirect removal process of $\mathrm{SiN}_{\mathrm{x}}$.
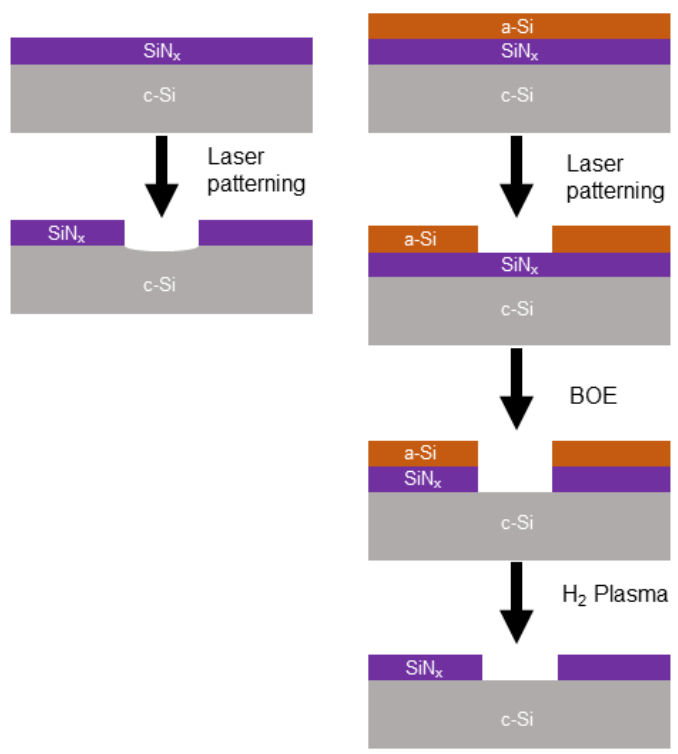

(a)

(b)

FIG. 1. Processing scheme for laser removal of $\mathrm{SiN}_{\mathrm{x}}$, (a) direct laser removal of SiNx with the laser, (b) indirect removal of $\mathrm{SiN}_{\mathrm{x}}$ using a laser ablated a-Si:H etch mask and Buffered Oxide Etch (BOE).

By using a film that can directly absorb the laser under normal conditions, it is possible to remove that film without relying on vaporization of the underlying c-Si substrate. Once the laser sensitive a-Si:H mask is patterned with the laser, the $\mathrm{SiN}_{\mathrm{x}}$ can be patterned with a Buffered Oxide Etch (BOE) owing to the chemical etching of $\mathrm{SiN}_{\mathrm{x}}$ in hydrofluoric acid (HF).

\section{Theory}

Given the high intensity and short duration of our femtosecond laser, we calculate and report the instantaneous intensity of the laser as shown in equation (1) using the assumption that the laser has a flat-top profile (neglecting a $\sim 32 \%$ power variation within the full-width-half-max measured spot size).

$P_{d}=\frac{P_{a v g}}{\left(n * t_{p} * f\right)}$

Here $P_{d}$ is the instantaneous power density, $P_{\text {avg }}$ the measured time average power, $n$ the number of triggered pulses per pulse train, $t_{p}$ the duration of the pulse, and $f$ the frequency of the pulse trains from the laser system. 
The intensity variation of the laser with a textured substrate complicates the power optimization process for our direct and indirect $\mathrm{SiN}_{\mathrm{x}}$ removal processes. For the direct removal process an increase in the film removal is accompanied by a corresponding increase in damage. For our indirect removal process, we use undercutting — etching of $\mathrm{SiN}_{\mathrm{x}}$ beneath the a-Si:H mask at the laser opened sites - to compensate for residual film. Undercutting of the a-Si:H film increases as the etch time increases, and eventually results in a-Si:H lift off at the lasing sites.

\section{Results and Discussion}

\subsection{Film bandgaps}

We deposited a-Si:H and $\mathrm{SiN}_{\mathrm{x}}$ films on separate polished c-Si substrates and characterized them with a variable angle spectroscopic ellipsometer to determine their respective index of refraction and absorption coefficient values.

From figure 2 we empirically determine the optical bandgaps of our $\mathrm{SiN}_{\mathrm{x}}$ and a-Si:H films to be greater than $3.06 \mathrm{eV}$ and $1.54 \mathrm{eV}$, respectively, by using a threshold absorption coefficient $(\alpha)$ value of $10^{4} \mathrm{~cm}^{-1}[12]$.

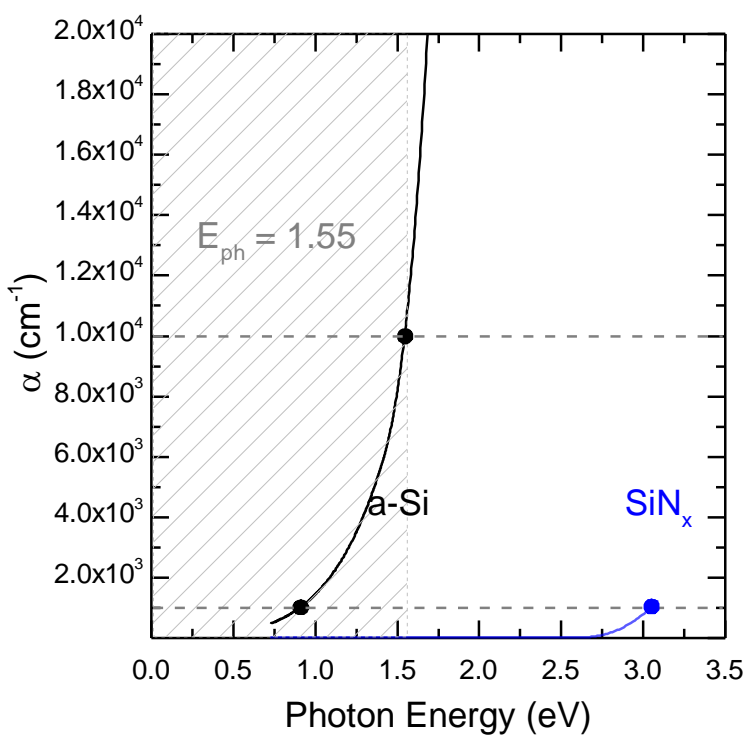

FIG. 2. Absorption coefficient plot of PECVD $\operatorname{SiN}_{\mathrm{x}}$ and a-Si:H compared to the photon energy of the laser. The crosshatched region indicates the regime where the laser is absorbed and the horizontal dashed lines indicate the lower and upper absorption coefficient thresholds of $10^{3}$ and $10^{4} \mathrm{~cm}^{-1}$ for determination of an empirical optical bandgap [12].

For our purposes the under-estimation of the bandgap of our $\mathrm{SiN}_{\mathrm{x}}$ makes little difference as the bandgap is well above the photon energy of the laser, preventing direct absorption in the film. In our a-Si:H film, the optical bandgap shifts from 0.91 to $1.54 \mathrm{eV}$ for depending on the threshold value of absorption selected $\left(10^{3}\right.$ or $\left.10^{4} \mathrm{~cm}^{-1}\right)$, both of which are less than the energy of our laser, allowing for direct absorption in the a-Si:H film. The c-Si also absorbs the laser (c-Si has an optical bandgap of $1.12 \mathrm{eV}$ ), necessitating a power optimization for the ablation of the a-Si:H film to reduce/remove c-Si damage. 


\subsection{Direct removal of $\mathrm{SiN}_{\mathrm{x}}$}

Due to the wide bandgap of the $\operatorname{SiN}_{\mathrm{x}}$ film, normal direct absorption of our laser does not occur in the thin film, but rather, occurs in the silicon substrate. It is possible with a femtosecond laser to achieve direct absorption of sub-bandgap photons in a wide bandgap material, but for applications where the substrate (in this case c-Si) has a smaller bandgap than the thin film, absorption may occur in the substrate on a large enough scale to induce damage to the substrate [13]. In our case, substantial surface damage was readily visible with SEM imaging.

In figure 3 the 1.2 and 1.3 shots indicate a 20 and $30 \%$ spot overlap, respectively; 5 shots indicate that each location in the laser line was exposed to 5 shots from the laser. Overlaps of 20 and $30 \%$ are used in order to achieve a consistent line. Figure 3 (a) and (b) demonstrate a direct removal of the $\mathrm{SiN}_{\mathrm{x}}$ film.
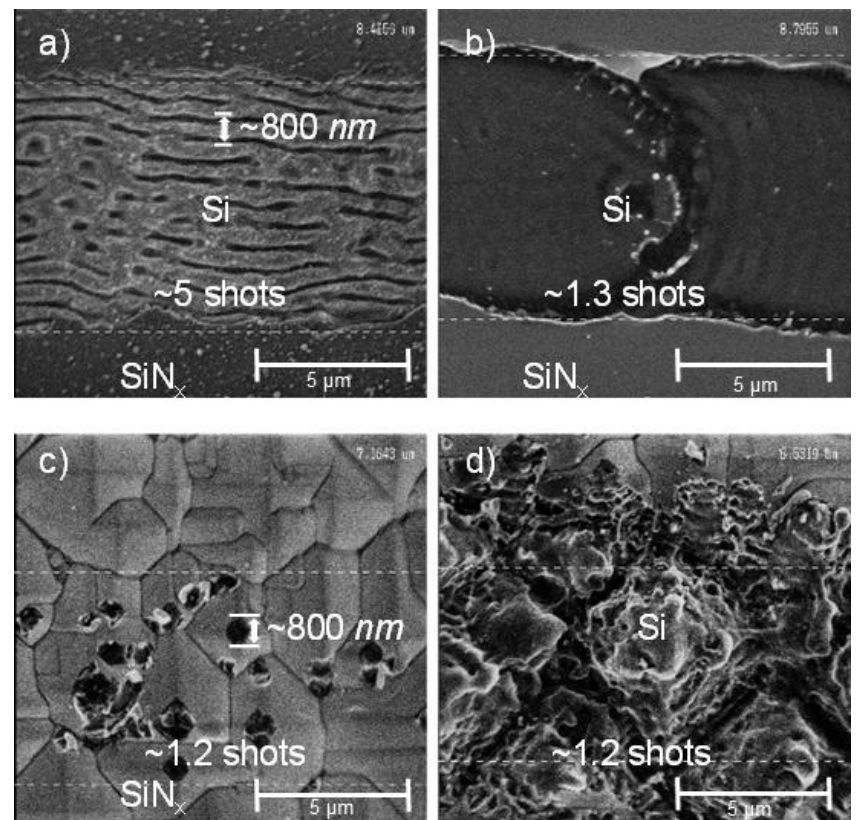

FIG. 3. (a) $\mathrm{SEM}$ image of a laser ablation spot $\left(\lambda=800 \mathrm{~nm}\right.$ ) after 5 shot minimum power $\mathrm{SiN}_{\mathrm{x}}$ ablation on smooth $\mathrm{Si}$, (b) SEM image 1.3 shot minimum power $\mathrm{SiN}_{\mathrm{x}}$ ablation, (c) SEM image of 1.2 shot minimum power ablation of $\mathrm{SiN}_{\mathrm{x}}$ on alkaline textured $\mathrm{Si}$, (d) SEM image of 1.2 shot minimum power full ablation of $\mathrm{SiN}_{\mathrm{x}}$ on alkaline textured $\mathrm{Si}$.

The peeling at the edge of the lasing site indicates that the film is lifted off from the underlying c-Si via c-Si vaporization. Repeatable film removal on smooth substrates is achievable with $P_{d}=$ $264 \mathrm{GW} / \mathrm{cm}^{2}$ as seen in (a) with multiple laser shots per location but this results in periodic trenching every $800 \mathrm{~nm}$ (the wavelength of the laser). We hypothesize that this trenching degrades the device performance of the solar cell by perforating the emitter. Operating under the assumption that the $\mathrm{SiN}_{\mathrm{x}}$ film removal is the result of vaporization of the underlying c-Si and a more energetic vaporization would result in more successful film removal we increased the laser intensity; in (b) the intensity was increased to $834 \mathrm{GW} / \mathrm{cm}^{2}$, and the shot repetition was limited to $\sim 1$. The single shot approach removed the periodic trenching.

With the introduction of alkaline texturing of the substrate (and the associated laser intensity variation), the direct removal of the $\mathrm{SiN}_{\mathrm{x}}$ becomes more challenging. The same $834 \mathrm{GW} / \mathrm{cm}^{2}$ power density that fully removed the $\mathrm{SiN}_{\mathrm{x}}$ in (b) resulted in partial ablation in (c) and an 
increased laser intensity of $1 \mathrm{TW} / \mathrm{cm}^{2}$ results in the ablation seen in (d). While trenching is avoided in (d), it is evident from the SEM imaging that the c-Si surface has been damaged. Direct removal of our $\mathrm{SiN}_{\mathrm{x}}$ on alkaline textured silicon leaves us with a defect rich surface.

\subsection{Indirect removal of $\mathrm{SiN}_{\mathrm{x}}$}

Given that the conditions used to generate figure 3 (c) resulted in incomplete ablation and those used for $(d)$ resulted in surface damage, we propose an alternate processing scheme. Vecci et al. demonstrated that the etch rate of $\mathrm{SiN}_{\mathrm{x}}$ films decreases as the $\mathrm{NH}_{3} / \mathrm{SiH}_{4}$ deposition gas ratio decreases - as the ratio approaches zero so does the etch rate [14]. Coupling this fact with the favorable bandgap of a-Si:H shown in figure 2, allows us to use a-Si:H as an etch mask as shown schematically in figure 1.

By patterning a $5 \mathrm{~nm}$ a-Si:H with the laser before we fire the $\mathrm{SiN}_{\mathrm{x}}$, we can use $\mathrm{HF}$ to selectively remove the $\mathrm{SiN}_{\mathrm{x}}$ where the a-Si:H has been ablated. If the a-Si:H is incompletely ablated, then we extend the etch time to undercut the residual film and fully open the contact without visible surface defects.

The white distortion and blurring in figure 4 (a) demonstrates charging of the local opening in the a-Si:H film from the laser ablation of the film. The charging is indicative of a nonconductive film and is the result of exposure of the underlying $\mathrm{SiN}_{\mathrm{x}}$ film. Devoid of charging, (b) contains a much clearer image, as the $\mathrm{SiN}_{\mathrm{x}}$ film has been locally removed with BOE. The a-Si:H film is then removed with a low power hydrogen plasma, leaving the $\mathrm{SiN}_{\mathrm{x}}$ intact.
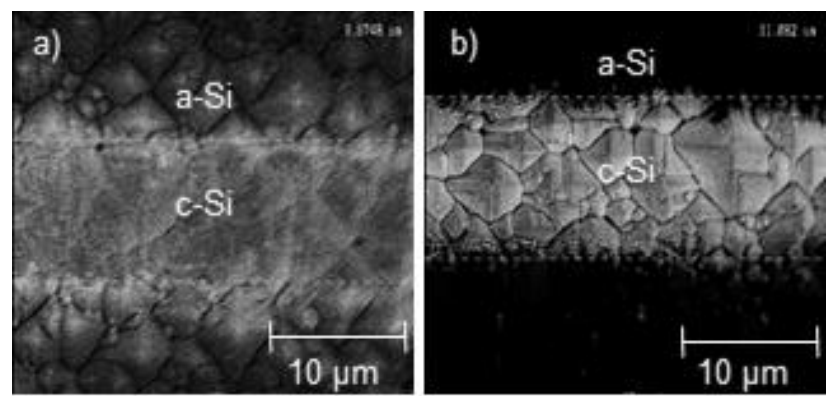

FIG. 4. (a) SEM image of a laser ablation line $(\lambda=800 \mathrm{~nm})$ of an a-Si:H sacrificial layer on top of $\mathrm{SiN}_{\mathrm{x}}$ on textured $\mathrm{Si}$ with $P_{d}=210 \mathrm{GW} / \mathrm{CM}^{2}$, (b) SEM image of a laser ablation line of a-Si:H on top of $\mathrm{SiN}_{\mathrm{x}}$ on textured silicon after a 2 minute BOE.

The $5 \mathrm{~nm}$ a-Si:H mask did not prove to be robust enough for fully blocking HF across the substrate, and created pinholes in the $\mathrm{SiN}_{\mathrm{x}}$ film. Pinholes coupled with Light-Induced-Plating (LIP) lead to ghost plating - the deposition/growth of metal in non-contact locations. Ghost plating reduces finger conductivity, causes pattern loss, and shades the cell, all of which are undesirable in our application [15-17].

The $156 \times 156 \mathrm{~mm}^{2}$ pseudo square cells pictured in figure 5 were formed using the laser process indicated in figure 1 (b) followed by LIP $\mathrm{Ni}$ and $\mathrm{Cu}$ on c-Si(p) cells with a bulk resistivity of 1-3 ohm-cm and an n-type emitter possessing a sheet resistance of $60 \mathrm{ohms} / \mathrm{square}$. The busbars of the cells are $1 \mathrm{~mm}$ (as shown by the arrows) and the fingers are $\sim 35 \mu \mathrm{m}$. The cell in figure 5 (a) has substantial ghost plating and pattern loss whereas (b) does not. While the increase in the a-Si:H mask thickness decreases the non-contact area plating, it also makes laser removal of the a-Si:H more challenging with the same laser intensity. 

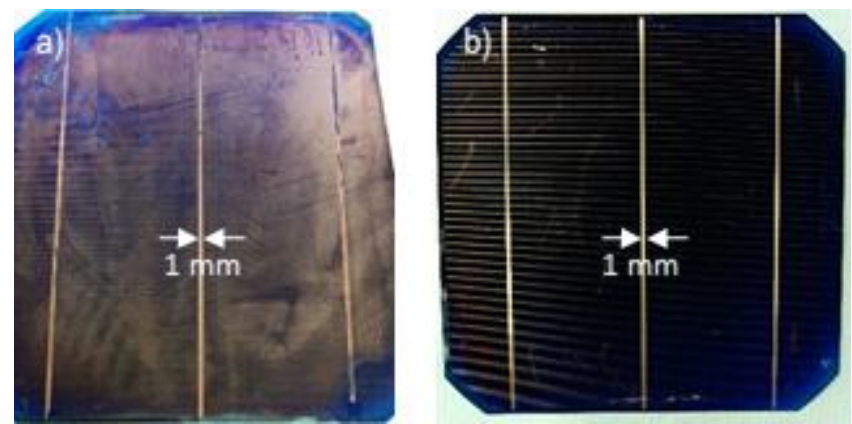

FIG. 5. (a) Tilted camera image of plated cell with a $5 \mathrm{~nm}$ a-Si:H etch mask, (b) Overhead camera image of plated cell with a $20 \mathrm{~nm}$ a-Si:H etch mask

Not surprisingly, for a fixed laser intensity of $210 \mathrm{GW} / \mathrm{cm}^{2}$ an increase in a-Si:H film thickness causes an increase in the residual film after processing - as demonstrated in figure 6. Figure 6 (a) with its $20 \mathrm{~nm}$ mask has substantially less film residue after the BOE process compared to the $40 \mathrm{~nm}$ mask in (b). Eventually the increase in mask thickness will completely obscure the contact region for plating, and prevent proper contact to the emitter.
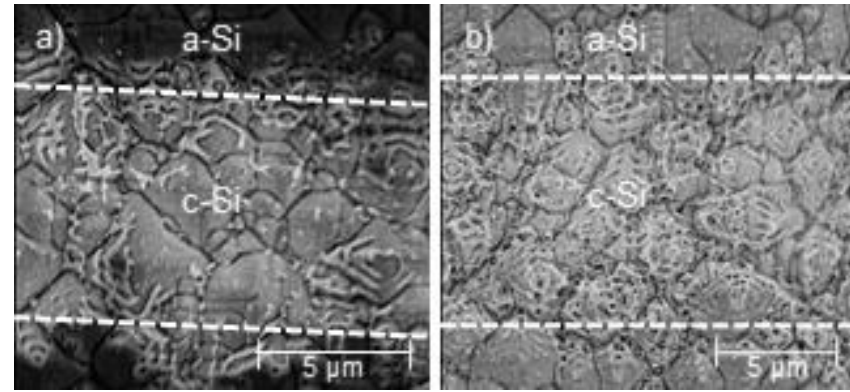

FIG. 6. (a) SEM image of a laser ablation line with $20 \mathrm{~nm}$ a-Si:H etch mask after BOE etch, (b) SEM image of a laser ablation line with $40 \mathrm{~nm}$ a-Si:H etch mask after BOE. Approximate line widths $(\sim 10 \mu \mathrm{m})$ are denoted by the white dashed lines.

Figure 7 (a), (b), and (c) each share the same BOE etch time and demonstrated that an increase in laser intensity increases the local opening in the $\mathrm{SiN}_{\mathrm{x}}$ for a fixed $\mathrm{BOE}$ etch time. Unfortunately, close inspection of (b) and (c) showed the emergence of small visible laser induced defects (LID) at the peaks of the pyramids as highlighted by the circles in figures 7 and 8. Dashed white lines highlight the approximate line width $(\sim 10 \mu \mathrm{m})$ for figure 7 (a) \& (b). The dashed white lines in figure 7 (c) bound a defect $\sim 200 \mathrm{~nm}$ in diameter, a quarter the wavelength of the laser. 

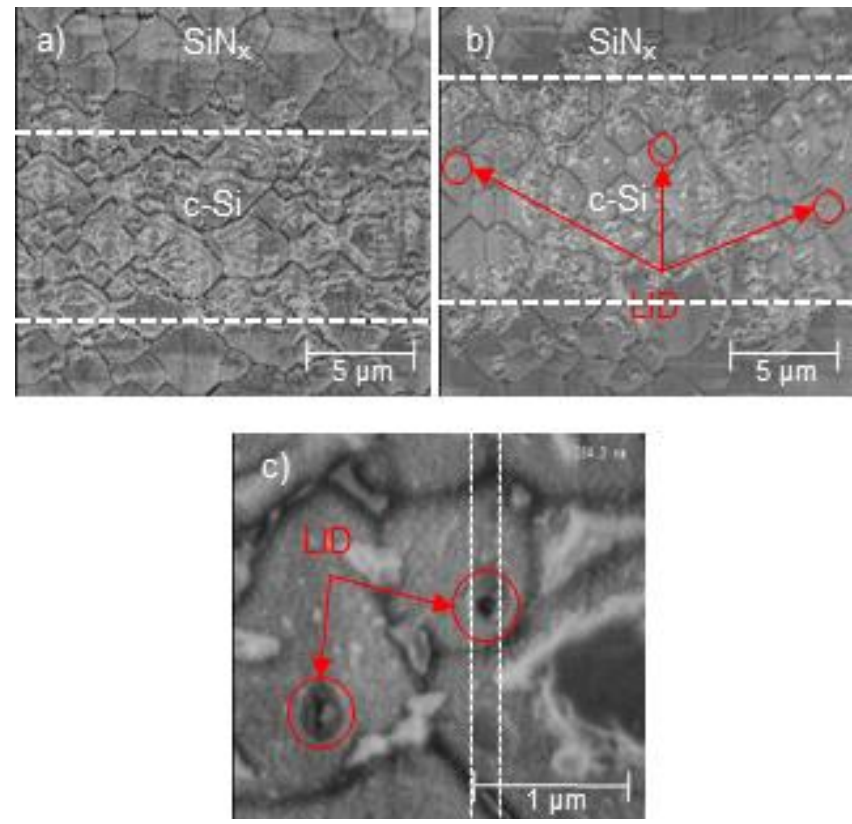

FIG. 7. SEM images of a laser ablation line with $40 \mathrm{~nm}$ a-Si:H etch mask after BOE and $\mathrm{H}_{2}$ plasma etch with (a) $P_{d}$ $=210 \mathrm{GW} / \mathrm{CM}^{2}$, (b) $P_{d}=662 \mathrm{GW} / \mathrm{cm}^{2}$, and (c) $P_{d}=662 \mathrm{GW} / \mathrm{cm}^{2}$ under higher magnification.

Although the low laser intensity used for contact opening in figure 7 (a) generated no visible defects, the same sample exhibits defects where the laser pulses overlap i.e., where the fingers and busbars intersect-increasing the sensitivity of our etch mask to the laser would allow for a decrease in laser intensity which may mitigate this issue. Figure 8 shows the defects generated at this intersection resultant from pulse overlap; this behavior is similar to the defect generation observed in figure 3 (a) for smooth surfaces. Dashed white lines highlight the approximate line widths $(\sim 10 \mu \mathrm{m})$ for figure 8 (a) and the boxed region represents the line intersection of a finger with a busbar. The dashed white lines in (b) show the approximate size of the defects to be $\sim 200$ nm.
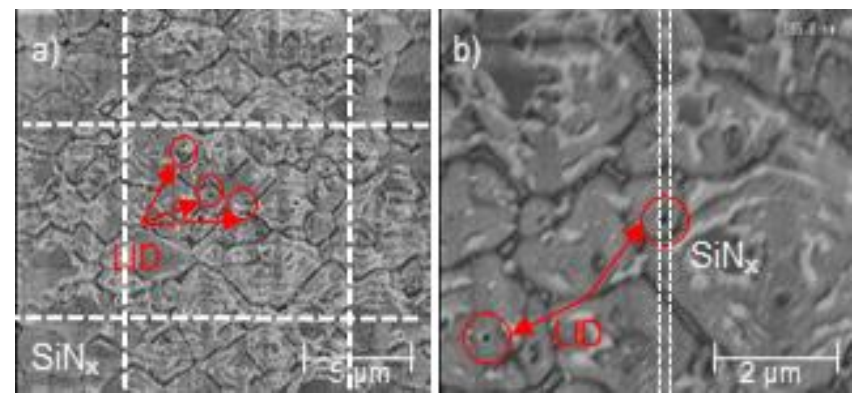

FIG. 8. (a) SEM image of finger/busbar intersection with $40 \mathrm{~nm}$ a-Si:H etch mask after BOE and $\mathrm{H}_{2}$ plasma etch with $P_{d}=210 \mathrm{GW} / \mathrm{CM}^{2}$ (b) SEM image of finger/busbar intersection with $20 \mathrm{~nm}$ a-Si:H etch mask after BOE and $\mathrm{H}_{2}$ plasma etch with $P_{d}=210 \mathrm{GW} / \mathrm{CM}^{2}$.

\subsection{SEM of plating}

Figure 9 (a) and (b) show the formation of 20-25 $\mu \mathrm{m}$ micro-wires with an 8-12 $\mu \mathrm{m} \mathrm{SiN}_{\mathrm{x}}$ opening without the presence of ghost plating, (c) and (d) show the presence of ghost plating and the effect it has on finger formation. As the a-Si:H etch mask becomes too thin, pinholes formed 
in the $\mathrm{SiN}_{\mathrm{x}}$ as a result of pinholes in the a-Si:H etch mask. These pinholes re-directed the plating current from the LIP process and reduced the conductivity, width, and consistency of the microwires. The spacing between the wires in (b) and (d) that comprise the busbar reduces the film stress in the busbar and improves metal adhesion. Samples without this spacing would experience peeling at the busbar after a 5 minute $350^{\circ} \mathrm{C}$ anneal, samples with adequate spacing to prevent wire-merging did not have this issue. Preliminary cell results with this process yielded an efficiency up to $16.9 \%$ before annealing. More detailed analysis of the impact of the laser process on the electrical performance of solar cells are pending a more complete LIP process, as well as a lighter doped emitter.
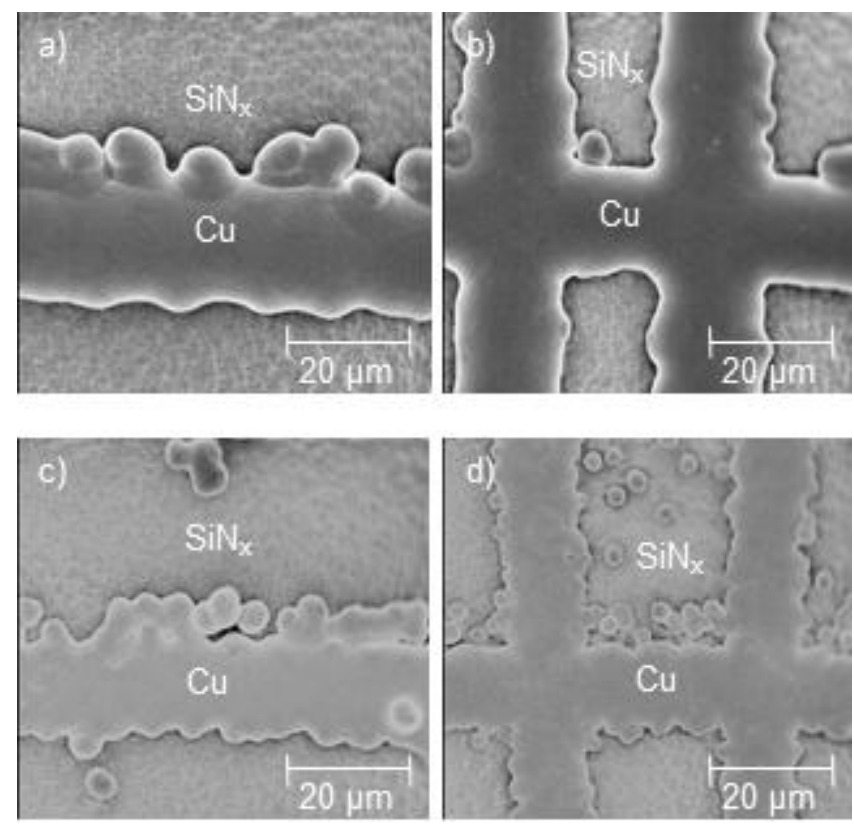

FIG. 9. (a) SEM image of finger without ghost plating using a $20 \mathrm{~nm}$ a-Si:H etch mask, (b) SEM image of finger/busbar intersection without ghost plating using a $20 \mathrm{~nm}$ a-Si:H etch mask, (c) SEM image of finger with ghost plating using a $7.5 \mathrm{~nm}$ a-Si:H etch mask, (d) SEM image of finger/busbar intersection with ghost plating using a 7.5 nm a-Si:H etch mask.

\section{Conclusions}

We largely mitigated the generation of surface defects and improved the quality of our c-Si surface with our indirect ablation technique. Our technique demonstrated an improvement in overall film removal and addresses the laser intensity variation in the film removal process with undercutting of the a-Si:H mask. The indirect ablation process demonstrated minor visual defects where the laser spot overlaps.

The reduction of damage decreases the need for post-ablation damage etches or selective emitter doping. Applications for this process would allow for the patterning of both $\mathrm{SiN}_{\mathrm{x}}$ and $\mathrm{SiO}_{\mathrm{x}}$, enabling selective doping for local openings without the need for additional equipment to support resist patterning steps.

Further work to enhance the absorption of the laser in the a-Si:H is necessary to decrease the power required for film ablation, reduction in c-Si damage, and minimization of residual film at the contact location. 
Acknowledgements: The authors would like to thank Dr. Zachary Holman for his assistance in editing and reviewing this work, Dr. Clarence Tracey for his assistance with equipment, and Barry Obrien for his film characterization work. The authors would also like to thank the national science foundation for their support of this work.

\section{REFERENCES}

[1] J. L. Hernandez and C. Allebe, Laser ablation and contact formation for Cu-plated large area C-silicon industial solar cells, 35th IEEE Photovoltaic Specialists Conference 53 (2010) 3158-3162.

[2] N. Bay, J. Horzel, and M. Sieber, Reliable Contact Formation for Industrial Solar Cells by Laser Ablation and Ni/Cu Plating, 29th European Photovoltaic Solar Energy Conference Exhibition (2014) 1272-1276.

[3] C. Geisler, W. Hördt, S. Kluska, A. Mondon, S. Hopman, and M. Glatthaar, Overcoming electrical and mechanical challenges of continuous wave laser processing for $\mathrm{Ni}-\mathrm{Cu}$ plated solar cells, Solar Energy Materials \& Solar Cells 133 (2015) 48-55.

[4] S. Kluska, J. Bartsch, A. Büchler, G. Cimiotti, A. A. Brand, S. Hopman, and M. Glatthaar, Electrical and Mechanical Properties of Plated Ni / Cu Contacts for Si Solar Cells, Energy Procedia 77 (2015) 733-743.

[5] C.-H. Lin, S.-P. Hsu, J.-J. Liou, C.-P. Chuang, W.-H. Lu, and W.-L. Chang, Characterization of selectiveemitter solar cells consists of laser opened window and subsequently screen-printed electrodes, 35th IEEE Photovoltaic Specialists Conference 53 (2010) 3523-3526.

[6] J. Kim, K. Y. Cho, E. J. Lee, K. K. Hong, H. W. Lee, J. M. Shim, D. J. Oh, J. E. Shin, J. S. Kim, J. K. Seo, S. H. Lee, B. Hallam, S. Wenham, and H. S. Lee, The effect of emitter diffusion formation methods for laser doped selective emitter silicon solar cells, 38th IEEE Photovoltaic Specialists Conference (2012) 21782181.

[7] A. Knorz, M. Peters, A. Grohe, C. Harmel, and R. Preu, Selective laser ablation of SiNx layers on textured surfaces for low temperature front side metallizations, Progress in Photovoltaics: Research and Applications 17 (2009) 127-136.

[8] S. Hermann, T. Dezhdar, N. P. Harder, R. Brendel, M. Seibt, and S. Stroj, Impact of surface topography and laser pulse duration for laser ablation of solar cell front side passivating SiNx layers, Journal of Applied Physics 108 (2010) 114514.

[9] S. Baumann, D. Kray, and K. Mayer, Comparative study of laser induced damage in silicon wafers, IEEE 4th World Conference on Photovoltaic Energy Conference 1 (2006) 1142-1145.

[10] A. Büchler, S. Kluska, M. Kasemann, M. Breitwieser, W. Kwapil, A. Hähnel, H. Blumtritt, S. Hopman, and M. Glatthaar, Localization and characterization of annealing-induced shunts in Ni-plated monocrystalline silicon solar cells, Physica Status Solidi Rapid Research Letters 8 (2014) 385-389.

[11] O. Utéza, B. Chimier, and N. Sanner, About the mechanisms of femtosecond laser damage and ablation of dielectric materials, The European Conference on Lasers and Electro-Optics 13 (2011) 82902.

[12] C. Ballif, W. Beyer, F. Finger, H. Schade, A. Shah, and N. Wrsch, Thin-film Silicon Solar Cells, EPFL Press, Lausanne, Switzerland, 2003.

[13] M. Lebugle, N. Sanner, O. Utéza, and M. Sentis, Guidelines for efficient direct ablation of dielectrics with single femtosecond pulses, Applied Physics A: Materials Science and Processing 114 (2014) 129-142.

[14] S. De Vecchi, T. Desrues, F. Souche, D. Muñoz, and M. Lemiti, Laser assisted patterning of hydrogenated amorphous silicon for interdigitated back contact silicon heterojunction solar cell, Proceedings of SPIE The International Society for Optical Engineering 8473 (2012) 84730R.

[15] M. C. Raval, S. S. Saseendran, S. Suckow, S. Saravanan, C. S. Solanki, and A. Kottantharayil, N2O plasma treatment for minimization of background plating in silicon solar cells with $\mathrm{Ni}-\mathrm{Cu}$ front side metallization, Solar Energy Materials \& Solar Cells 144 (2016) 671-677.

[16] M. C. Raval, A. Joshi, and C. S. Solanki, Analyzing impact of background plating from alkaline Ni bath for Ni-Cu metallization, 2013 IEEE 39th Photovoltaic Specialists Conference (2013) 2254-2256.

[17] S. Braun, A. Zuschlag, B. Raabe, and G. Hahn, The origin of background plating, Energy Procedia 8 (2011) $565-570$. 